\title{
HISTOMORPHOLOGICAL CORRELATION OF PIH PLACENTA AND LOW DOSE ASPIRIN TREATED PLACENTA
}

\author{
A.L. Santhi ${ }^{1}$, Banumathi ${ }^{2}$
}

\section{HOW TO CITE THIS ARTICLE:}

A.L. Santhi, Banumathi."Histomorphological Correlation of PIH Placenta and Low Dose Aspirin Treated Placenta". Journal of Evolution of Medical and Dental Sciences 2014; Vol. 3, Issue 01, January 06;

Page: 158-164.

\begin{abstract}
OBJECTIVES: To correlate the histomorphological changes in PIH Placenta and low dose Aspirin received placenta.METHODS: This prospective study was conducted in 50 patients. They were divided into two groups. 25 placentas were collected from PIH patients and 25 placentas from patients who were treated with prophylactic low dose aspirin [75 mg] from 28 th week of gestation. Results; Improved vascular bloodflow with reduced vessel wall changes and infarctswere noticed in the placenta of aspirin group. So there was a good placental weight and baby weight leading to a good neonatal outcome.
\end{abstract}

KEYWORDS: Placenta, Aspirin, Pregnancy induced Hypertension. [PIH]

INTRODUCTION: Pregnancy induced hypertension [PIH] accounts for 6-8\% of all pregnancies.PIH remains a major cause of morbidity and mortality for both mother and baby. Mother may develop DIC, HELLP syndrome, renal or hepatic failure. Baby may suffer from IUGR, IUD and prematurity. ${ }^{1}$

Although the cause of PIH remains obscure, it is primarily a placental disorder. During implantation, deficient trophoblastic invasion of maternal spiral arteries leads to underperfusion of uteroplacental circulation and placental ischemia². So in PIH, placenta affected by ischemia shows variety of changes both morphologically and histologically which can be appreciated by light microscopy and special stains.

Women with PIH have deficient intravascular production of prostacyclin, a vasodilator and an excessive production of thromboxane, a vasoconstrictor and platelet agonist. Low dose Aspirin therapy in these patients is beneficial by potent antiplatelet effect. It inhibits platelet production of thromboxane. Thus the loss of maternal and fetal lives to PIH can most often be prevented ${ }^{3}$.

So detailed study of placenta was undertaken in PIH patients by using special stains. The degree of severity of PIH was correlated clinicopathologically. These histopathological changes in placenta were compared with aspirin treated groups to know the effects of treatment.

AIMANDOBJECTIVES: The principal aim is to study the various histopathological changes that occur in the placenta of PIH patients and compare them with the placenta of PIH patients who received low dose Aspirin. Battery of special stains was used to delineate the hypoxic changes and blood vessel changes in placenta of PIH cases.

MATERIALAND METHODS: A prospective study of placenta of PIH patients [Mild and Severe] were compared with the placenta of PIH patients on low dose Aspirin $75 \mathrm{mg} /$ day from 28 $8^{\text {th }}$ week of gestation. Placentaswere collected in the third trimester after delivery. The age group ranges from 15-32 years, maximum number of cases was between 21- 25 years of age. 


\section{ORIGINAL ARTICLE}

Thorough examination of the placenta was done. Weight of the placenta after trimming the membranes, maximum diameter, thickness at the centre, shape, accessory lobe, infarcts [size, location, number], calcification, cyst, tumor and intervillous fibrin. Placentas from normotensive individuals were also collected and used as control. Special stains were also used in control placentas for comparison.

\section{RESULTS:}

Weight of the Placenta:The mean average weight of the placenta in PIH group was 360 gms and in Aspirin group was 485 gms.

\begin{tabular}{|c|c|c|}
\hline Weight of the placenta & In PIH Patients group & InAspirin group \\
\hline $150-250 \mathrm{Gms}$ & $24 \%$ & $\mathrm{Nil}$ \\
\hline $250-350 \mathrm{Gms}$ & $12 \%$ & $4 \%$ \\
\hline $350-450 \mathrm{Gms}$ & $44 \%$ & $28 \%$ \\
\hline $450-550 \mathrm{Gms}$ & $16 \%$ & $64 \%$ \\
\hline$>550 \mathrm{Gms}$ & $4 \%$ [Diabetes associated] & $4 \%$ \\
\hline
\end{tabular}

\section{HISTOPATHOLOGICAL FINDINGSOF PLACENTA IN PIH:}

1.CYTOTROPHOBLASTIC PROLIFERATION: Minimal proliferationwas observed in $72 \%$ and severe in $28 \%$ of PIH cases. Whenever placenta suffers an ischemic damage as in PIH, germinal zone will be reactivated and cytotrophoblasts will proliferate in an attempt to repair and replace the injured syncytial tissue 4 .

2.EXCESSIVE NUMBER OF SYNCYTIAL KNOTS:Minimal increase in syncytial knots were observed in $64 \%$ cases and marked increase in $36 \%$ of cases.
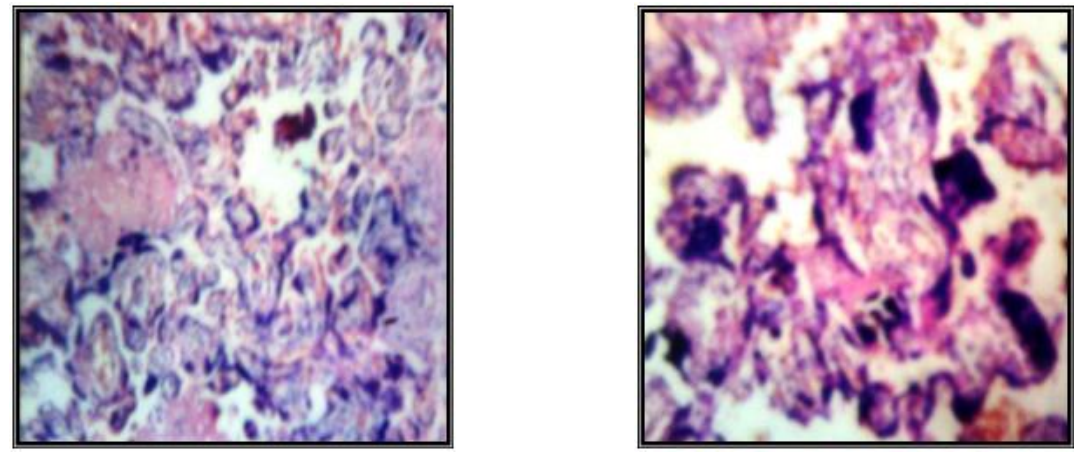

\section{Fig. 1 \& 2: EXCESSIVE SYNCYTIAL KNOTS LOW POWER, HIGH POWER}

3. THICKENING OF BASEMENT MEMBRANE:Noticed in $50 \%$ of cases of PIH which are better appreciated by PAS [Periodic Acid Schiff] staining. Basementmembrane protein is secreted by proliferatedcyotrophoblasts 5 . 


\section{ORIGINAL ARTICLE}

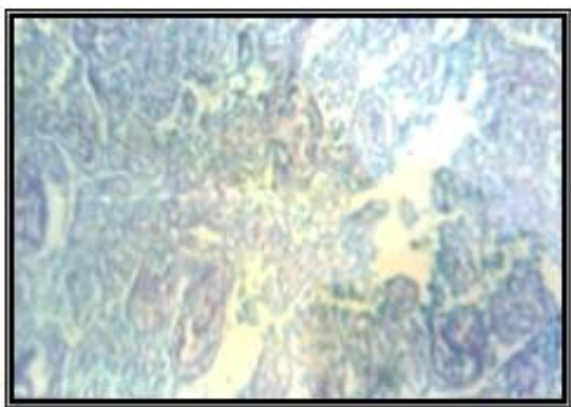

Fig. 3: Control PAS Placenta

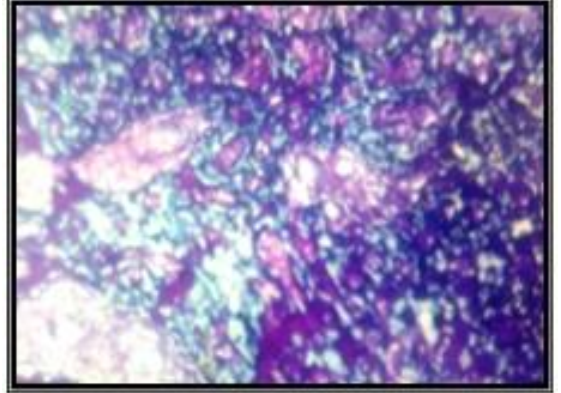

Fig. 4: PAS In PIH Placenta showing Basement membrane thickening

\section{ABNORMALITIES OF BLOOD VESSELS:}

A.MEDIAL HYPERTROPHY: Concentric onion skin appearance sometimes even totally occluding the lumen. This was best brought out by special stain -VERHOFFE'Selastic stain in $68 \%$ of cases.
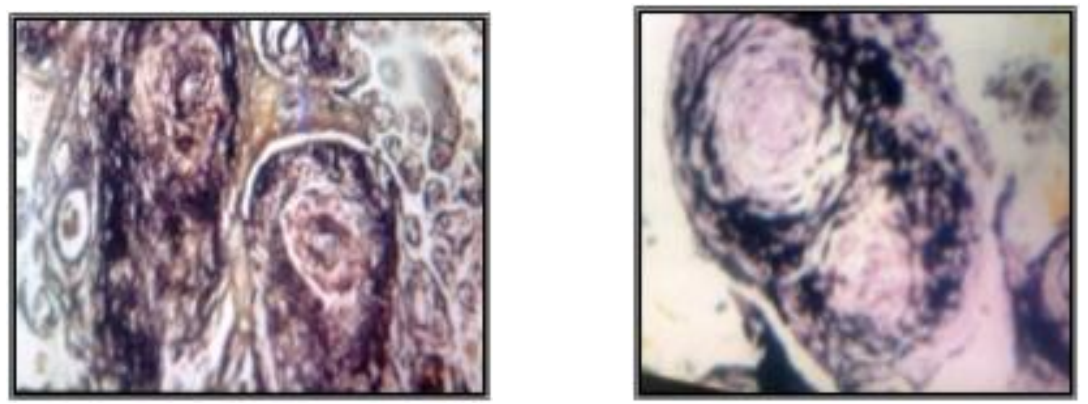

Fig. 5 \& 6: Verhoeffe's Elastic Stain; Shows medial hypertrophy and complete occlusion

B.FIBRINOID NECROSIS: Seen in 52\% of cases. PTAH [Phosphotungstic acid Haematoxylin] was used to demonstrate this necrosis.

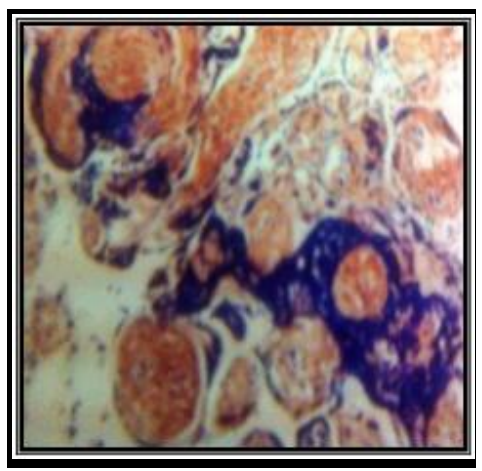

Fig. 7:PTAH - Fibrinoid Necrosis $10 \mathrm{X}$

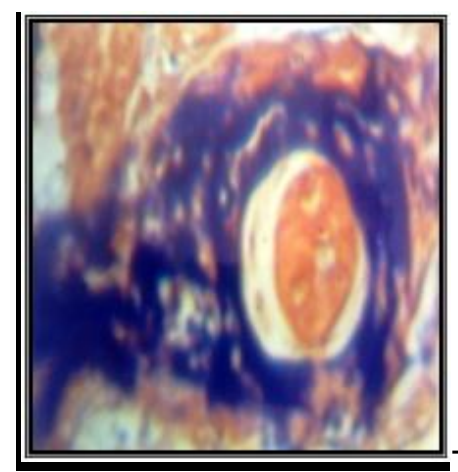

Fig. 8: PTAH - $40 \mathrm{X}$ 


\section{ORIGINAL ARTICLE}

5.PLACENTAL INFARCTS: Infarction is most common in PIH [34-60\%] are significantwhen they are more than $3 \mathrm{~cm}$. Old infarcts are firm \& white. In PIH, multiple diffuseinfarcts were present. Fresh infarcts are red, congested and soft. In our study fresh infarcts were seen in $12 \%$ and old infarcts in $68 \%$ of PIH cases. Minimal infracted areas were observed in aspirin group. Infarcts were associated with significant perinatal morbidity and mortality.

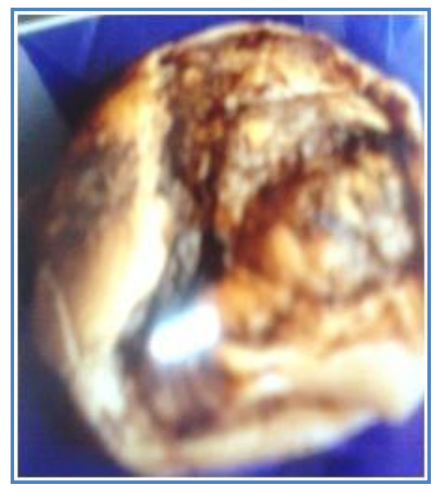

Fig. 9:PIH PLACENA WITH EXTENSIVEPALEINFARCTS

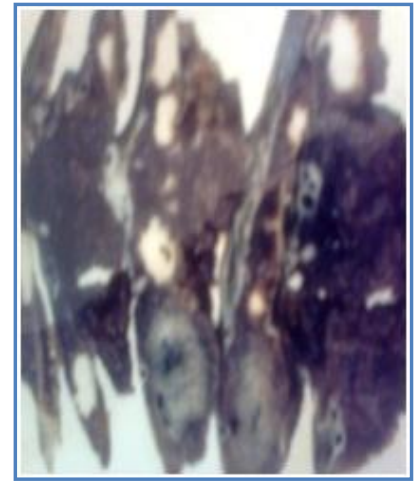

Fig. 10: Cut section Revealing Old Infarcts

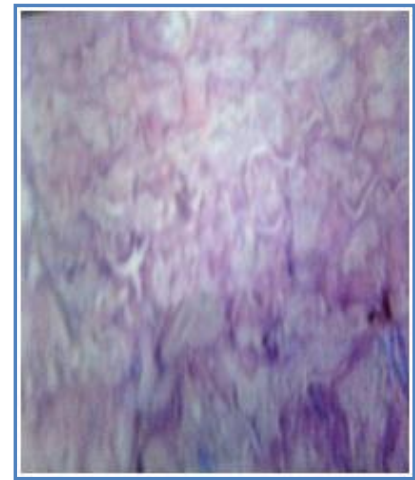

Fig. 11: H \& E Section of Old Infarcted area

\begin{tabular}{|l|c|c|}
\hline \multicolumn{1}{|c|}{ HISTOPATHOLOGICAL CHANGES } & MILD & SEVERE \\
\hline CYTOTROPHOBLASTIC PROLIFERATION & $72 \%$ & $28 \%$ \\
\hline SYNCYTIAL KNOTS & $64 \%$ & $36 \%$ \\
\hline BASEMENT MEMBRANE THICKENING & $30 \%$ & $26 \%$ \\
\hline MEDIAL HYPERTROPHY & $38 \%$ & $30 \%$ \\
\hline FIBRINOID NECROSIS & $28 \%$ & $24 \%$ \\
\hline OLD INFARCTS & $36 \%$ & $44 \%$ \\
\hline \multicolumn{2}{|c|}{ VILLOUS OBSERVATION IN PIH CASES } \\
\hline
\end{tabular}

\section{HISTOPATHOLOGICAL CHANGES OBSERVED IN ASPIRIN GROUP:}

1. Increased vascularity of villi.

2. Cytotrophoblastic proliferation: Absent in $56 \%$ cases and minimal in $32 \%$ cases.

3. Syncytial knots: Absent in $68 \%$ of cases and minimal in $32 \%$ of cases.

4. Fibrinoid Necrosis: $84 \%$ of placenta did not show fibrinoid necrosis. $16 \%$ showed minimal fibrinoid changes.

5. Medial Hypertrophy: No medial hypertrophy in $76 \%$ of cases and minimal in $24 \%$ of cases.But there was no occlusion of lumen in these cases. In general, atherosis of blood vessel has reduced.

6. Old Infarcts: Observed only in $8 \%$ of Aspirin group.

7. Basement Membrane Thickening: No thickening seen in $72 \%$ of cases and minimal in $28 \%$ of cases. 


\section{ORIGINAL ARTICLE}

\begin{tabular}{|l|c|c|}
\hline HISTOPATHOLOGICAL CHANGESIN ASPIRIN GROUP & ABSENT & MINIMAL \\
\hline CYTOTROPHOBLASTIC PROLIFERATION & $56 \%$ & $44 \%$ \\
\hline SYNCYTIAL KNOTS & $68 \%$ & $32 \%$ \\
\hline BASEMENT MEMBRANE THICKENING & $72 \%$ & $28 \%$ \\
\hline FIBRINOIDNECROSIS & $84 \%$ & $16 \%$ \\
\hline MEDIAL HYPERTROPHY & $76 \%$ & $24 \%$ \\
\hline OLD INFARCTS & $92 \%$ & $08 \%$ \\
\hline
\end{tabular}

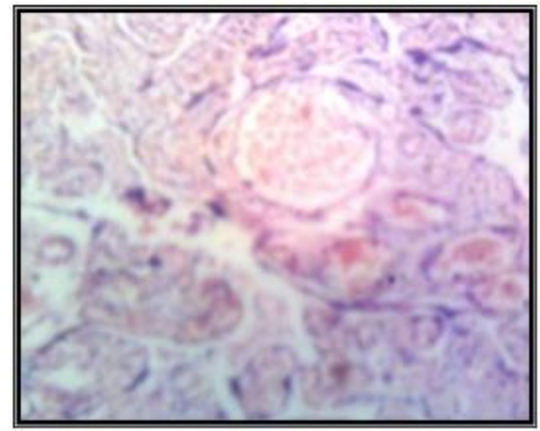

Fig. 12: H \& E section of Placenta inAspirin group.

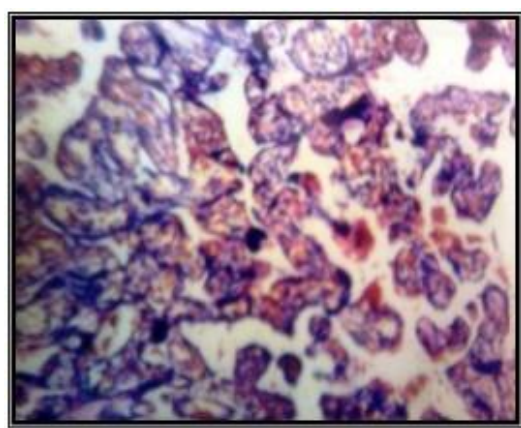

Fig. 13: Increased vascularity with minimal Syncytial knots in Aspirin Group.

FETALOUTCOME:In 25 cases of PIH, 15babies were alive, 4 cases of intrauterine Death and 6 cases of deeply asphyxiated babies were noticed. Two asphyxiated were revived and 4 babies were lost. Placenta of intrauterine death fetuses were below average weight. Placenta had retroplacental hematomas and in one case, it occupied almost the entire half of placenta. Histology of these placentas showed massive old infarcts, medial hypertrophy of blood vessels, basement membrane thickening and fibrinoid necrosis.

\begin{tabular}{|c|c|c|}
\hline BIRTH WEIGHT & IN PIH GROUP & PIH PATIENTS ON ASPIRIN \\
\hline $1.5-2 \mathrm{~kg}$ & $24 \%$ & $4 \%$ \\
\hline $2-2.5 \mathrm{Kg}$ & $56 \%$ & $12 \%$ \\
\hline $2.5-3 \mathrm{Kg}$ & $16 \%$ & $68 \%$ \\
\hline$>3 \mathrm{~kg}$ & $4 \%$ & $16 \%$ \\
\hline \multicolumn{3}{|c|}{ BABY WEIGHT CHART } \\
\hline
\end{tabular}

DISCUSSION:In PIH, major pathological changes are seen in placenta. Villi in the placenta are subjected to reduced maternal uteroplacental blood flow and so they showa characteristic pattern of abnormalities due to hypoxia. There is undue prominence and increase of villous cytotrophoblasts along with thickening of basement membrane. The cytotrophoblastic cells are the stem cells where DNA synthesis and mitotic activity occurs. Syncytiotrophoblast being formed by breaking down of limiting membrane of cytotrophoblasts and it is a post mitotically differentiated tissue. Therefore cytotrophoblast is considered to form a germinative zone, though in late stages of pregnancy it is largely quiescent ${ }^{5}$. 


\section{ORIGINAL ARTICLE}

If placenta suffers an ischemicdamage as in PIH, the germinative zone will be reactivated andcytotrophoblastic cells proliferate in an attempt to repair and replace the injured syncytial tissue $^{5}$. Basement membrane thickening seen in placenta subjected to ischemiais an incidental byproductof cytotrophoblastic hyperplasia. Basement protein is almost secreted by cytotrophoblasticcells. The essential response of placenta to ischemia is a reparative one.

PATHOGENESIS OF PIH:Placental ischemia secondary to defective placentation, a prerequisite for the development of preeclampsia has a multifactorial origin. In a normal pregnancy, the trophoblastic invasion is associated with striking changes in the arteries supplying the intervillous space.The endothelium is replaced by trophoblast. By contrast, these changes develop defectively in preeclamptic woman and are also limited to decidual portion of spiral arterioles. Blood vessels are sometime occluded by fibrinoid material and surrounded by foam cells. These features are known as acute atherosis.These changes have been well brought about by special stain, PTAH, which stains fibrinoid material.

One consequence of abnormal invasion of the spiral arteries is deficient uteroplacental circulation.So the villous growth in low oxygen environment as in PIH exhibits the following features;

1. Cytotrophoblastic proliferation

2. Increase in number of syncytial knots

3. Basement membrane Thickening.

ENDOTHELIAL CELL DYSFUNCTION - FINAL COMMON PATHWAY: Many observations point to a central role of endothelial cells in the pathogenesis of PIH. Endothelial injury leads to an increase of potent vasoactive substance such as endothelin, fibronectin and thromboxane. Endothelin is a potent vasoconstrictor and three distinct endothelins exist 1, 2 and 3. Patients with preeclampsia have higher levels of endothelin. A marker of endothelial dysfunction is Fibronectin, a high molecular weight protein ${ }^{6}$. Thromboxane causes vasoconstriction, stimulates platelet aggregation and uterine contractility. Prostacyclin produces opposite physiological effects. Maternal plasma prostacyclin is decreased in both mild and severe cases of preeclampsia whereas thromboxane is increased. Thromboxane is synthesized as a result of endothelial injury?

ROLE OF LOWDOSE ASPIRIN IN PROPHYLAXIS AND EARLY TREATMENT OF PIH:It appears that two vasoconstrictormechanisms may be operative in woman with PIH i.e.especially in PIH, arachidonic acid is converted via cyclooxygenase pathway into thromboxane A2 with an accompanying reduction in prostacyclin[PGI2] and prostaglandin E2.This pathway is responsive to low dose aspirin therapy. Arachidonic acid may be converted into PGI2, PGE2 and TXA2. Low dose aspirin thereby block TXA2 production more than the production of PGI2 and PGE2.

Since aspirin has been shown to be beneficial in preventing eclampsia, it is important to be able to predict which patients are at risk for the disease. The most commonly used non-laboratory method is blood pressure measurement. Any rise in blood pressure after $20^{\text {th }}$ week of gestation should raise the concern for preeclampsia. Another means of predicting the risk is based on mean arterial pressure in second trimester. Another routine diagnostic test is roll over test. Pregnant woman whose diastolic pressure increases when they change from left lateral to supine position are 
at high risk for preeclampsia. Laboratory methods of prediction includeelevated serum uric acid levels, fibronectin levels and decreased urine calcium excretion ${ }^{8}$.

Therefore low dose aspirin therapy has been proved to be useful in improving the placental blood flow and thereby fetal outcome and baby weight.

CONCLUSION:Low dose Aspirin therapy in PIH patients showed the following findings;

1. Improved vascular blood flow.

2. Reduced vessel wall changes.

3. Reduces the incidence of Placental infarcts.

4. Good Placental weight.

5. Improved Baby weight.

6. Good Neonatal outcome.

\section{REFERENCES:}

1. William's Obstetrics and Gynaecology 19thEdition pg. 763-806.

2. Tridinger 1988. Low dose Aspirin improves fetal weight in placental insufficiency AM J obs.Gyn.159;651-685.

3. Low dose Aspirin in Pregnancy- SIBAI ET Al 1989- 74; 551-556.

4. Pathology of Placenta by Eugene V.D.K.Perrin.Vol.5;66-87.

5. FOX 's Placental pathology.5th Edition Vol II Pg. 1336- 1344.

6. Aspirin for treatment of Recurrent toxaemia- Goodlin et al - Lancet ii $1 ; 51$

7. Elder Et al 1988; Low dose Aspirin in pregnancy. Lancet 1;44

8. Pregnancy Induced Hypertension by R. R. Gaiser, T.G.Cheek and B.B.Gutsche.pg262-270

\section{AUTHORS:}

1. A.L. Santhi

2. Banumathi

\section{PARTICULARS OF CONTRIBUTORS:}

1. Professor and HOD, Department of Pathology, Thanjavur Medical College, Tamilnadu.

2. Professor, Department of Pathology, Thanjavur Medical College, Tamilnadu.

\section{NAME ADDRESS EMAIL ID OF THE CORRESPONDING AUTHOR:}

Dr. A.L. Santhi,

10, Philomina Nagar,

Don Bosco School Road,

Thanjavur.

Email-santhiminu@gmail.com

Date of Submission: 20/10/2013.

Date of Peer Review: 21/10/2013.

Date of Acceptance: 04/12/2013.

Date of Publishing: 02/01/2014 